Document downloaded from:

http://hdl.handle.net/10251/64995

This paper must be cited as:

Aghaali, H.; Angström, H.; Serrano Cruz, JR. (2015). Evaluation of different heat transfer conditions on an automotive turbocharger. International Journal of Engine Research. 16(2):137-151. doi:10.1177/1468087414524755.

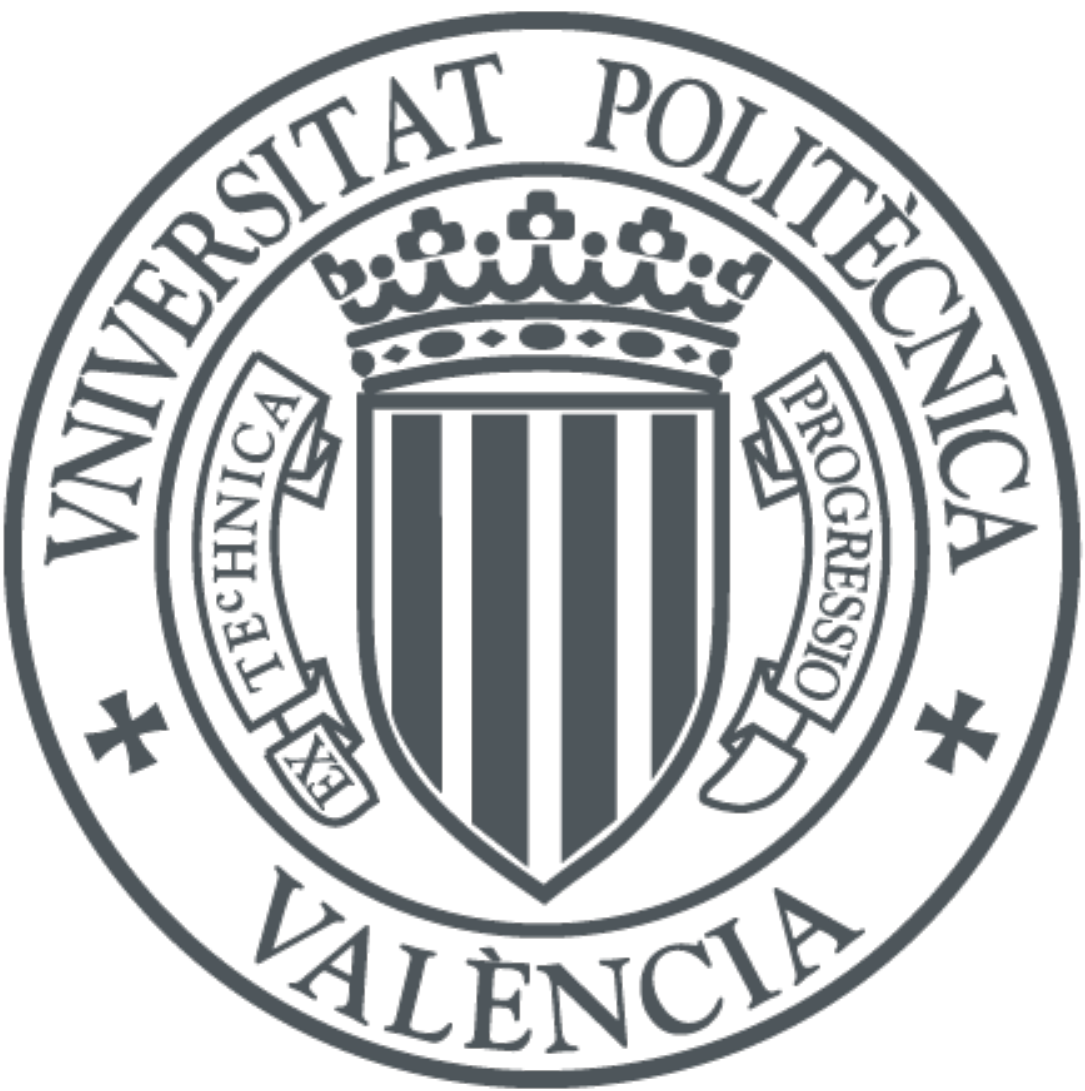

The final publication is available at

http://dx.doi.org/10.1177/1468087414524755

Copyright SAGE Publications (UK and US)

Additional Information 


\title{
Evaluation of different heat transfer conditions on an
}

\section{automotive turbocharger}

\author{
Habib Aghaali ${ }^{1}$, Hans-Erik Ångström ${ }^{1}$, and Jose Ramon Serrano ${ }^{2}$
}

\begin{abstract}
This paper presents a combination of theoretical and experimental investigations for determining the main heat fluxes within a turbocharger. These investigations consider several engine speeds and loads as well as different methods of conduction, convection, and radiation heat transfer on the turbocharger. A one-dimensional heat transfer model of the turbocharger has been developed in combination with simulation of a turbocharged engine that includes the heat transfer of the turbocharger. Both the heat transfer model and the simulation were validated against experimental measurements. Various methods were compared for calculating heat transfer from the external surfaces of the turbocharger, and one new method was suggested.

The effects of different heat transfer conditions were studied on the heat fluxes of the turbocharger using experimental techniques. The different heat transfer conditions on the turbocharger created dissimilar temperature gradients across the turbocharger. The results show that changing the convection heat transfer condition around the turbocharger affects the heat fluxes more noticeably than changing the radiation and conduction heat transfer conditions. Moreover, the internal heat transfers from the turbine to the bearing housing and from the bearing housing to the compressor are significant, but there is an order of magnitude difference between these heat transfer rates.
\end{abstract}

\section{Keywords}

Turbocharger, Heat transfer, On-engine turbocharger, Heat flux, Convection

\section{Introduction}

In the race to cut pollutant emissions and improve the fuel economy of internal combustion engines, there is a general agreement among researchers that engine downsizing should be a part of this process. Turbocharging is the most promising technology for enabling engine downsizing. Turbochargers are currently used on a wide variety of both compression ignition and spark ignition engines, and naturally aspirated engines are becoming obsolete. A

\footnotetext{
${ }^{1}$ Royal Institute of Technology, KTH-CCGEx, Internal Combustion Engine, Stockholm, Sweden

${ }^{2}$ Universitat Politècnica de València, CMT-Motores Térmicos, València, Spain

Corresponding author: H Aghaali, Royal Institute of Technology, KTH-CCGEx, Internal Combustion Engine, Stockholm, Sweden,

Email: aghaali@kth.se
} 
turbocharger consists of a compressor that is mechanically connected to a turbine. The engine's exhaust gases run the turbine that in turn runs the compressor to force more air into the engine. Thus a turbocharger is beneficial in two ways: the turbocharger's compressor provides more compressed air to the engine allowing for downsizing to a smaller engine, and the turbocharger's turbine utilizes the engine's exhaust gases for waste heat recovery.

The exhaust gases from the engine often reach temperatures as high as 700 to $900{ }^{\circ} \mathrm{C}$, whereas the compressed air is much cooler and ranges between 30 and $150{ }^{\circ} \mathrm{C}$. This leads to a large temperature gradient across the turbocharger and significant heat transfer from the hot turbine to the compressor. The bearing housing between the turbine and compressor is cooled by oil (and in some models by water), and the heat transfer rates between these materials adds to the complexity of measuring the temperature gradient that forms on the turbocharger. In addition, the operating conditions of the turbine and the compressor can affect this temperature gradient.

Heat transfer occurs via conduction, convection, and radiation, and the rate at which heat is transferred by these mechanisms depends on the combination of material temperatures, material properties, body geometry, and/or fluid properties. The study of heat transfer in turbochargers has become an important aspect of turbocharged engine development, and there has been growing interest in the heat transfer analysis of automotive turbochargers $[1,2,3,4,5,6,7]$. Other issues in regards to heat transfer in turbochargers are also important, including the effect of heat transfer on the turbocharger performance $[7,8,9]$, turbocharger performance correction for non-adiabatic conditions [9], and turbocharged engine simulations [10].

Romagnoli and Martinez-Botas [1,2] showed that the engine itself has a large impact on the surface temperature of the turbocharger's turbine and compressor housings. They also found that the surface temperatures of both the turbine and the compressor have a linear relationship to the exhaust gases temperature [1,2]. These observations have been confirmed under varying engine loads and speeds, but not in the presence of different heat transfer conditions on the turbocharger. In addition, the temperature gradients in their experiments were measured between the inner and outer walls of the turbine and the compressor housings $[1,2]$. The surface temperature of the bearing housing was also found to vary consistently with that of the cooling oil [1,2]. Baines et al. [3] carried out the same experiment as in those previous publications [1,2], but in their work three different turbochargers were run over a range of turbine inlet temperatures and external ventilation rates. The heat transfer coefficients required in their onedimensional heat transfer model were found to be mostly independent of the turbochargers tested [3].

A thermal characterization procedure for turbochargers has been presented by Serrano et al. [4]. This procedure allows for the determination of the turbocharger's thermal properties without the influence of operative factors such as the compressibility of the fluids passing through the compressor and turbine housings, heat transfer from the turbocharger to the lubricant oil, or mechanical losses due to the rotor movement. Although radiation was not 
considered in this model [4], it has been concluded that it is necessary also to study the radiation heat transfer interactions in the turbocharger.

A three-dimensional conjugate flow and heat transfer calculation has been performed by Bohn et al. [5] for a turbocharger at three different turbine inlet temperatures and four different mass flows. It was concluded from that study that the compressor fluid is heated by the heat flux from the turbine at low Re numbers, but with increasing Re number the compression heats the fluid to an even greater degree and this heat is transferred to the compressor housing and blades [5]. The importance of heat transfer inside turbochargers has been highlighted especially for low loads [11]. It has been shown that the heat transfer from the exhaust gases inside the turbocharger could reach the $70 \%$ of the turbine enthalpy difference [11]. Temperature distribution on turbocharger walls has been investigated in different heat transfer conditions [12] and it was concluded that the heat transfer in turbochargers is particularly important in transient operations because the temperatures of the turbocharger working fluids are strongly influenced by the momentary temperatures of the turbocharger walls [12].

It remains unclear, however, what effects variations to the heat transfer conditions have on the heat fluxes across a turbocharger. Thus further investigations are needed to evaluate different heat transfer conditions on turbochargers and to calculate the resulting heat fluxes. In this paper, a one-dimensional heat transfer model of a turbocharger was developed and validated against measurements. Different calculation methods were used and a new method is suggested for calculating the Nu number of the turbocharger components. A secondary aim of this work was to extend the use of the model to an innovative design of experiment (DOE) that was based on a statistical analysis and was used in combination with a turbocharged engine simulation. The experiment was performed for various load points of the engine with different heat transfer conditions on the turbocharger. These conditions included an extra cooling fan to change the convection rate around the turbocharger, a radiation shield between the turbine and the compressor to prevent the radiation of heat from the turbine to the compressor and the bearing housing, and different water cooling settings to change the rate of conduction through the bearing housing.

\section{Experimental setup}

To study the heat transfer on the turbocharger under engine-like conditions, a test rig that could supply hot gases in the range of 700 to $900^{\circ} \mathrm{C}$ was required. Because such a test rig was not available, and the main focus was to apply the result of this investigation to a one-dimensional simulation of turbocharged engines running under different heat transfer conditions, it was decided to perform the tests on a real engine. However, this required significantly more work in terms of making accurate measurements, ensuring a pulsating flow, and maintaining controllability. The engine used for this work was a direct injection 2-litre gasoline engine equipped with a turbocharger. The turbocharger 
was water-oil-cooled with a closed (welded) waste-gate. Several thermocouples were welded on accessible surfaces of the turbocharger to measure the temperatures of the turbocharger walls. Table 1 provides the number of thermocouples used on the turbocharger surfaces.

Figure 1 shows the tested turbocharger with its thermocouples and on the engine with shielded straight ducts placed before and after the turbocharger's turbine and compressor. This was done because the turbocharger performance maps for the engine simulation had been measured on a closed-loop hot test rig with straight ducts [13], so using the straight ducts on the engine could lead to a more accurate simulation. The important parameters measured on the turbocharged engine are summarized in Table 2.

Table 1. Number of temperature sensors on the accessible surfaces of turbocharger walls.

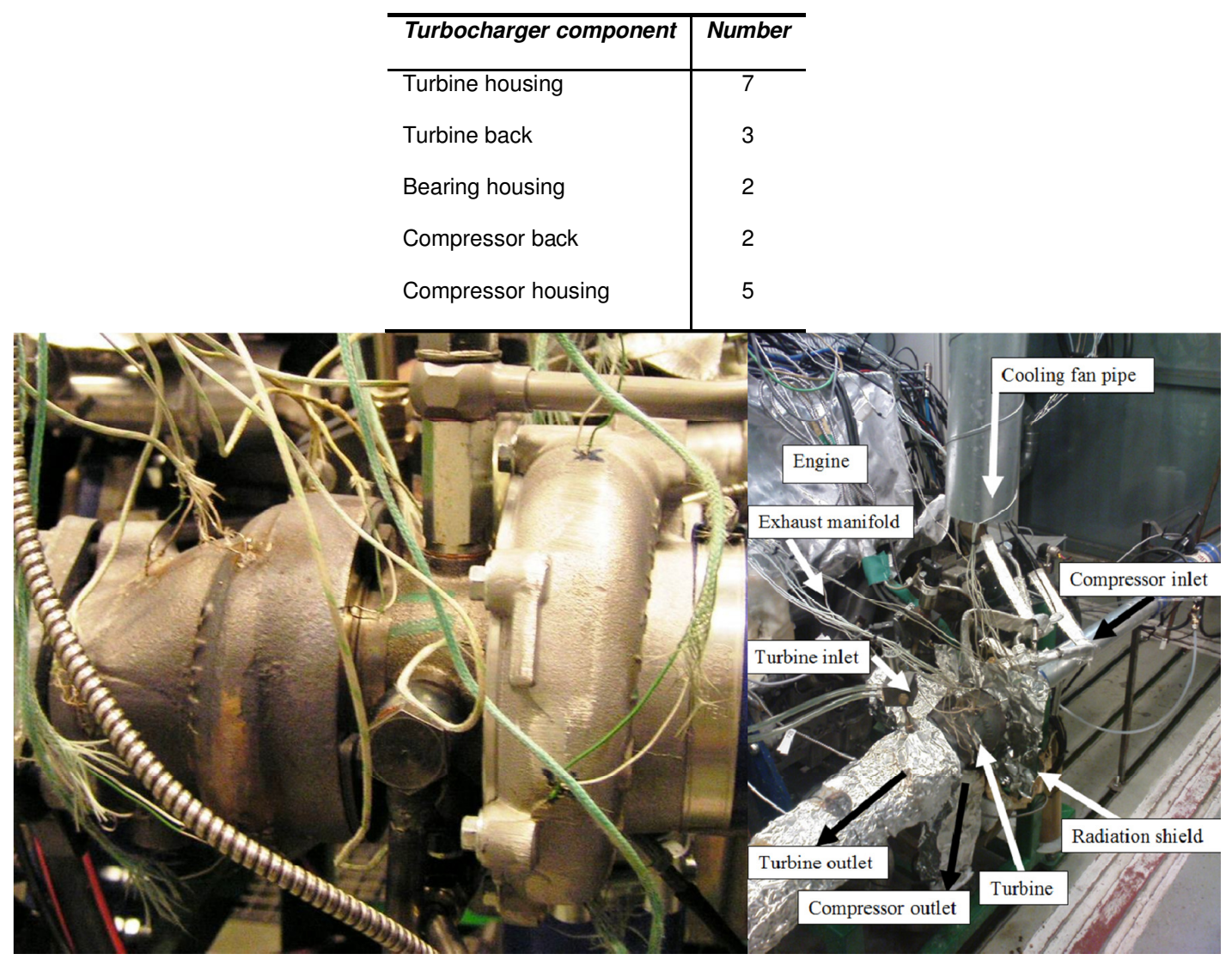

Figure 1. Tested turbocharger on the engine with its welded thermocouples on the accessible surfaces.

Table 2. Some important measured parameters on the turbocharged engine.

\begin{tabular}{|l|l|}
\hline Temperatures & $\begin{array}{l}\text { intake manifold, turbine inlet, turbine outlet, compressor inlet, compressor outlet, turbocharger surfaces, cooling water } \\
\text { of the turbocharger at inlet and outlet, turbocharger oil at inlet and outlet }\end{array}$ \\
\hline Pressures & compressor inlet, compressor outlet \\
\hline Crank angle resolved & cylinder, exhaust manifold, intake manifold, turbine inlet, turbine outlet \\
\hline Mass flows & inlet air, fuel, cooling water of the turbocharger, turbocharger oil \\
\hline Other parameters & turbocharger speed, valve timing, start of injection, air-fuel equivalence ratio (lambda), engine speed, engine torque \\
\hline
\end{tabular}


The experiment was performed at different engine speeds and loads and under different heat transfer conditions in the turbocharger, summarized in Table 3. Six strategies were used to study variation of heat transfer conditions on the turbocharger:

1. The turbocharger was run with or without water. In one case, the water passed into the turbocharger bearing housing, and in another the water flow was blocked. At all load points, the oil for cooling the bearing housing came from the engine oil, but the water came from a cooling system maintained at around $16{ }^{\circ} \mathrm{C}$. This was due to the existence of air bubbles in the engine water that interfered with the measurements. Although the magnitude of the heat transfer depends on the water temperature and mass flow, the two levels of water setting (on or off) were sufficient for the present study.

2. A radiation shield (aluminium foil) was placed between the turbine and the compressor to avoid radiation heat transfer from the hot turbine to the compressor and the bearing housing. The turbocharger was run with and without this radiation shield.

3. An extra cooling fan was mounted on top of the turbocharger to change the rate of convection heat transfer. The measured equivalent velocity of the air was $18 \mathrm{~m} / \mathrm{s}$ when the fan was on. The turbocharger was run with and without this cooling fan.

4. A wide radiation shield was used between the exhaust manifold of the engine and the turbocharger at all load points to avoid the radiation heat transfer from the exhaust manifold to the turbocharger.

5. Micapac 1000 gaskets that have low heat conductivity were placed between pipes and the turbocharger to reduce conduction from the turbocharger to the pipes or vice versa. The gaskets had a thermal conductivity of $0.3 \mathrm{~W} / \mathrm{m} \cdot \mathrm{K}$ at $20{ }^{\circ} \mathrm{C}$.

6. To reduce heat transfer via convection and radiation, all pipes to the turbocharger were insulated, including the oil and water pipes to the turbocharger bearing housing. This allowed for more accurate measurements and simulations of the turbocharged engine. For further details about the engine test, the reader is referred to [14].

\subsection{DOE}

DOE allows for the determination of the effects of many variables and their simultaneous interactions that could affect the results of the experiment (responses) [15]. In statistics a full-factorial experiment is one that consists of two or more variables that can exist at discrete values or levels and considers all possible combinations of these factors and their values [16].

To study the magnitudes of different heat and energy fluxes on the turbocharger, a single engine load point was measured under different heat transfer conditions. Table 4 summarizes the heat transfer conditions for an engine speed of $2000 \mathrm{rpm}$ and BMEP (break mean effective pressure) of 12.4 bar. This is, in fact, a full-factorial experiment on the heat transfer of the turbocharger. The three independent factors in the experiment are an extra cooling fan on 
top of the turbocharger, which is on or off, the water through the turbocharger bearing housing, which is either flowing or is blocked, and a radiation shield between the turbine and the compressor, which is used or not used. Thus for the experiment to consider all possible combinations of these factors eight trials must be run, summarized in Table 4 . Trial 8 in Table 4 is the normal condition of the turbocharger on the engine in which the water passes through the turbocharger bearing housing and the fan and the turbocharger radiation shield are not used. The responses are the external heat transfers from the turbine housing, the bearing housing, and the compressor housing and the internal heat transfers from the turbine to the bearing housing and from the bearing housing to the compressor.

Table 3. The experiment of the turbocharged engine under different load points and different heat transfer conditions on the turbocharger $(\checkmark=y e s)$.

\begin{tabular}{|c|c|c|c|c|c|c|c|c|c|}
\hline 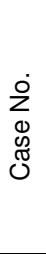 & 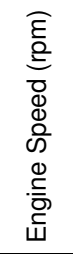 & 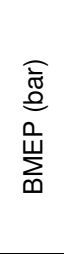 & 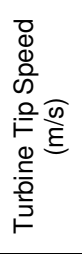 & 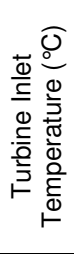 & 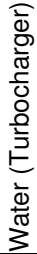 & 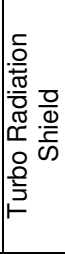 & 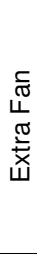 & 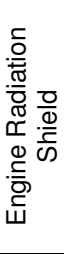 & 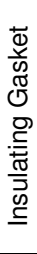 \\
\hline 1 & 2000 & 12.4 & 220.2 & 850 & $\checkmark$ & $\checkmark$ & & $\checkmark$ & $\checkmark$ \\
\hline 2 & 2000 & 12.4 & 220.0 & 850 & & $\checkmark$ & & $\checkmark$ & $\checkmark$ \\
\hline 3 & 2000 & 12.4 & 217.7 & 831 & & $\checkmark$ & $\checkmark$ & $\checkmark$ & $\checkmark$ \\
\hline 4 & 2000 & 12.4 & 216.7 & 830 & $\checkmark$ & $\checkmark$ & $\checkmark$ & $\checkmark$ & $\checkmark$ \\
\hline 5 & 2000 & 12.4 & 216.5 & 828 & $\checkmark$ & & $\checkmark$ & $\checkmark$ & $\checkmark$ \\
\hline 6 & 2000 & 12.4 & 216.5 & 826 & & & $\checkmark$ & $\checkmark$ & $\checkmark$ \\
\hline 7 & 2000 & 12.4 & 218.5 & 848 & & & & $\checkmark$ & $\checkmark$ \\
\hline 8 & 2000 & 12.4 & 218.0 & 848 & $\checkmark$ & & & $\checkmark$ & $\checkmark$ \\
\hline 9 & 2000 & 3.2 & 56.7 & 625 & $\checkmark$ & & & $\checkmark$ & $\checkmark$ \\
\hline 10 & 2000 & 3.2 & 57.5 & 624 & & & & $\checkmark$ & $\checkmark$ \\
\hline 11 & 2000 & 6.3 & 121.3 & 720 & $\checkmark$ & & & $\checkmark$ & $\checkmark$ \\
\hline 12 & 2000 & 6.3 & 123.2 & 720 & & & & $\checkmark$ & $\checkmark$ \\
\hline 13 & 2000 & 9.4 & 175.6 & 799 & $\checkmark$ & & & $\checkmark$ & $\checkmark$ \\
\hline 14 & 2000 & 9.4 & 176.1 & 798 & & & & $\checkmark$ & $\checkmark$ \\
\hline 15 & 2000 & 12.5 & 219.8 & 853 & $\checkmark$ & & & $\checkmark$ & $\checkmark$ \\
\hline 16 & 2000 & 12.4 & 220.8 & 854 & & & & $\checkmark$ & $\checkmark$ \\
\hline 17 & 2000 & 15.6 & 256.6 & 849 & $\checkmark$ & & & $\checkmark$ & $\checkmark$ \\
\hline 18 & 2000 & 15.6 & 256.2 & 849 & & & & $\checkmark$ & $\checkmark$ \\
\hline 19 & 1000 & 6.2 & 49.7 & 555 & $\checkmark$ & & & $\checkmark$ & $\checkmark$ \\
\hline 20 & 1000 & 6.2 & 52.1 & 558 & & & & $\checkmark$ & $\checkmark$ \\
\hline 21 & 1500 & 6.3 & 82.9 & 656 & $\checkmark$ & & & $\checkmark$ & $\checkmark$ \\
\hline 22 & 1500 & 6.3 & 84.4 & 654 & & & & $\checkmark$ & $\checkmark$ \\
\hline 23 & 2500 & 6.3 & 153.7 & 769 & $\checkmark$ & & & $\checkmark$ & $\checkmark$ \\
\hline 24 & 2500 & 6.4 & 154.5 & 769 & & & & $\checkmark$ & $\checkmark$ \\
\hline 25 & 3000 & 6.3 & 185.3 & 801 & $\checkmark$ & & & $\checkmark$ & $\checkmark$ \\
\hline 26 & 3000 & 6.2 & 185.7 & 800 & & & & $\checkmark$ & $\checkmark$ \\
\hline 27 & 3500 & 6.5 & 223.9 & 848 & $\checkmark$ & & & $\checkmark$ & $\checkmark$ \\
\hline 28 & 3500 & 6.3 & 224.6 & 850 & & & & $\checkmark$ & $\checkmark$ \\
\hline 29 & 4000 & 6.4 & 252.9 & 852 & $\checkmark$ & & & $\checkmark$ & $\checkmark$ \\
\hline 30 & 4000 & 6.2 & 253.2 & 849 & & & & $\checkmark$ & $\checkmark$ \\
\hline 31 & 3000 & 12.7 & 321.8 & 848 & $\checkmark$ & & & $\checkmark$ & $\checkmark$ \\
\hline 32 & 3000 & 12.5 & 322.7 & 849 & & & & $\checkmark$ & $\checkmark$ \\
\hline 33 & 3000 & 12.5 & 322.8 & 841 & $\checkmark$ & $\checkmark$ & & $\checkmark$ & $\checkmark$ \\
\hline 34 & 3000 & 12.5 & 322.2 & 848 & & $\checkmark$ & & $\checkmark$ & $\checkmark$ \\
\hline 35 & 3000 & 12.5 & 320.6 & 831 & & $\checkmark$ & $\checkmark$ & $\checkmark$ & $\checkmark$ \\
\hline 36 & 3000 & 12.5 & 320.5 & 831 & $\checkmark$ & $\checkmark$ & $\checkmark$ & $\checkmark$ & $\checkmark$ \\
\hline 37 & 3000 & 12.5 & 320.7 & 833 & $\checkmark$ & & $\checkmark$ & $\checkmark$ & $\checkmark$ \\
\hline 38 & 3000 & 12.5 & 320.9 & 834 & & & $\checkmark$ & $\checkmark$ & $\checkmark$ \\
\hline 39 & 3000 & 12.5 & 322.7 & 849 & & & & $\checkmark$ & $\checkmark$ \\
\hline 40 & 3000 & 12.5 & 321.8 & 848 & $\checkmark$ & & & $\checkmark$ & $\checkmark$ \\
\hline
\end{tabular}


The main effect of each factor on each response is the difference between the high and low levels of the factor [17]. For instance, the effect of having water flowing through the turbocharger bearing housing on the external heat transfer of the compressor is the difference of the average response of the compressor external heat transfer when the water is on and the average response of the compressor external heat transfer when the water is off, Equation (1). "Water" effect on $\mathrm{Q}_{\mathrm{Ext}, \mathrm{C}}=\left(\text { average } \mathrm{Q}_{E x t, C}\right)_{\text {Water on }}-\left(\text { average } \mathrm{Q}_{\text {Ext,C}}\right)_{\text {Water off }}$.

In addition, the effect of the interactions is the mean difference between the effect of the first factor when the second factor is on and the effect of the first factor when the second factor is off, Equation (2).

"Water $\times$ Fan" effect on $\mathrm{Q}_{\mathrm{Ext}, \mathrm{C}}=\left(\text { Water effect on } \mathrm{Q}_{\mathrm{Ext}, \mathrm{C}}\right)_{\text {Fan on }}-\left(\text { Water effect on } \mathrm{Q}_{\mathrm{Ext}, \mathrm{C}}\right)_{\text {Fan off }}$.

The multiplication sign between Water and Fan in Equation (2) signifies the interaction of "Water" and "Fan" variables.

Table 4. Different heat transfer conditions on the turbocharger at an engine speed of $2000 \mathrm{rpm}$ and a BMEP of 12.4 bar; All trials have a radiation shield between the engine and turbocharger and insulating gaskets between pipes and the turbocharger; $(\checkmark=$ =es).

\begin{tabular}{|c|c|c|c|c|c|c|c|}
\hline Trial No. & $\begin{array}{c}\text { Engine Speed } \\
(\mathrm{rpm})\end{array}$ & BMEP (bar) & $\begin{array}{l}\text { Turbine Tip Speed } \\
(\mathrm{m} / \mathrm{s})\end{array}$ & $\begin{array}{c}\text { Turbine Inlet } \\
\text { Temperature }\left({ }^{\circ} \mathrm{C}\right)\end{array}$ & $\begin{array}{c}\text { Water } \\
\text { (Turbocharger) }\end{array}$ & $\begin{array}{c}\text { Turbo } \\
\text { Radiation } \\
\text { Shield }\end{array}$ & $\begin{array}{l}\text { Extra } \\
\text { Fan }\end{array}$ \\
\hline 1 & 2000 & 12.4 & 220.2 & 850 & $\checkmark$ & $\checkmark$ & \\
\hline 2 & 2000 & 12.4 & 220.0 & 850 & & $\checkmark$ & \\
\hline 3 & 2000 & 12.4 & 217.7 & 831 & & $\checkmark$ & $\checkmark$ \\
\hline 4 & 2000 & 12.4 & 216.7 & 830 & $\checkmark$ & $\checkmark$ & $\checkmark$ \\
\hline 5 & 2000 & 12.4 & 216.5 & 828 & $\checkmark$ & & $\checkmark$ \\
\hline 6 & 2000 & 12.4 & 216.5 & 826 & & & $\checkmark$ \\
\hline 7 & 2000 & 12.4 & 218.5 & 848 & & & \\
\hline 8 & 2000 & 12.4 & 218.0 & 848 & $\checkmark$ & & \\
\hline
\end{tabular}

\section{Turbocharged engine simulation}

To provide some parameters that cannot be measured directly such as specific heat capacity of the exhaust gases, the turbocharged engine simulation is combined with the experimental and theoretical investigation of the heat transfer in the turbocharger. The turbocharged engine was simulated with the GT-POWER software package [18]. The simulation was based on one-dimensional gas dynamics representing the flow and heat transfer in the piping and other components of the engine system. The continuity, momentum, and energy equations were simultaneously solved by the software as one-dimensional equations in the flow model. However, turbine and compressor performances were modelled in this simulation software using performance maps that were measured on the hot testrig for turbocharger [13]. Both the compressor and turbine maps can be summarized as a series of performance data points, each of which describes the operating condition in terms of speed, pressure ratio, mass flow rate, and efficiency. The turbocharger speed and the pressure ratio are predicted across the turbine and compressor at each time-step, and the mass flow rate and efficiency values are looked up in the corresponding performance maps and used in the equations that are solved by the GT-POWER software. 
The outlet temperatures of the turbine and the compressor are calculated based on the turbine's and compressor's efficiencies, and this leads to deviations from the true outlet temperatures measurements. Heat transfer in the turbocharger is a major cause of these deviations, and when the heat transfer condition on the turbocharger is changed the turbocharger performance maps cannot accurately predict the turbine and the compressor outlet temperatures and they need to be corrected. One can find in the literature at least two methods to account for the heat transfer of the turbocharger in 1D engine simulation: correcting the performance maps for non-adiabatic conditions [9] or including the heat transfer of the turbocharger in the engine simulation while the performance maps are kept constant [10]. In this study the second method was used. The main assumptions of this method are that most of the heat transfer to the surrounding air takes place at the compressor scroll and that most of the heat transfer from the exhaust gas occurs in the turbine volute. Consequently, to take into account heat transfer on the turbocharger, a heat source immediately after the compressor and a heat sink just before the turbine are built into the model [10]. The simulated heat flow from the turbine and the simulated heat flow to the compressor are artificial heat flows that are required to correct for differential heat transfers in the turbocharger between the turbocharger test rig and the engine laboratory.

\section{Turbocharger heat transfer modelling}

Figure 2 shows the heat and energy fluxes on the turbocharger via different heat transfer mechanisms. Exhaust gases enter the turbine, produce power, and then exit from it. The power produced by the turbine drives a shaft that turns a compressor that takes in fresh air and releases compressed air. The power produced by the turbine is consumed by the compressor and friction on the turbocharger shaft.

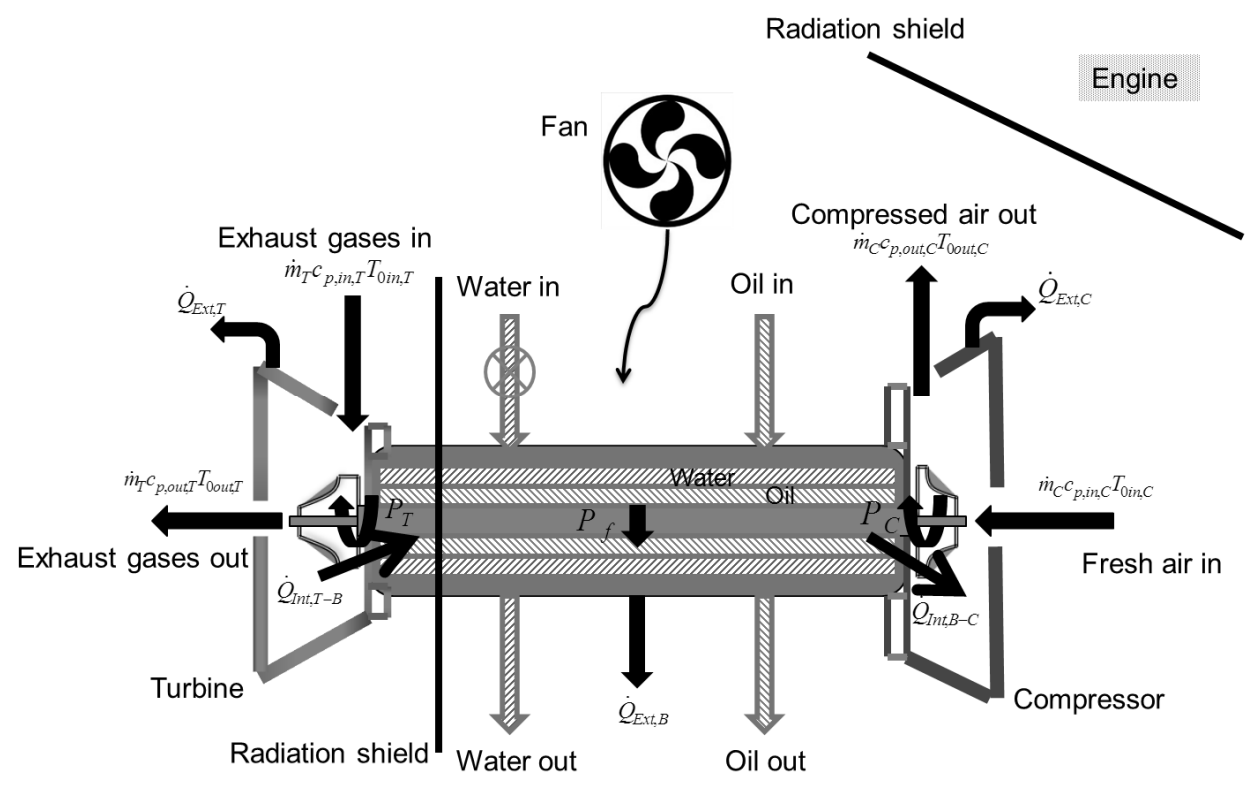

Figure 2. Heat and energy fluxes on the turbocharger in different heat transfer conditions. 
The main governing equations regarding the heat transfer in the turbocharger are balance equations in turbine, compressor and shaft (3,4 and 5) and one independent balance equation in the bearings housing (6). These equations are derived from the first law of thermodynamics and assume a control volume around each turbocharger component.

Assuming a control volume around the turbine:

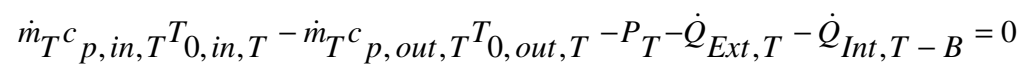

Assuming a control volume around the compressor:

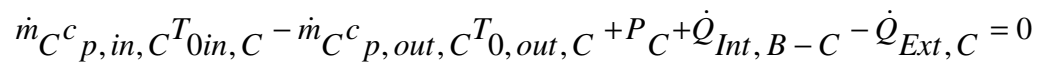

Assuming a control volume around the shaft power:

$P_{T}-P_{C}=P_{f}$

Assuming a control volume around the bearing housing:

$\dot{Q}_{I n t, T-B}-\dot{Q}_{I n t, B-C}+P_{f}-\dot{Q}_{W}-\dot{Q}_{O i l}-\dot{Q}_{E x t, B}=0$

In order to complete required inputs for the proposed system of equations, some parameters are needed and they can be extracted from the 1D code (GT-Power) for turbocharged engine simulation, such as turbine inlet and outlet temperatures, specific heat capacity of the exhaust gases before and after the turbine, specific heat capacity of the air before and after the compressor in different temperatures and humidity, turbine work and compressor work. Equation (5) gives the frictional power of the turbocharger. The external heat transfer can be calculated on the turbine, the compressor and the bearing housing $\left(\dot{\mathrm{Q}}_{\mathrm{Ext}, \mathrm{T}}, \dot{\mathrm{Q}}_{\mathrm{Ext}, \mathrm{C}}\right.$ and $\left.\dot{\mathrm{Q}}_{\mathrm{Ext}, \mathrm{B}}\right)$, based on the measured temperatures of the surfaces. Finally, the internal heat transfers can be calculated from the turbine to the bearing housing and from the bearing housing to the compressor $\left(\dot{\mathrm{Q}}_{\mathrm{Int}, \mathrm{T}-\mathrm{B}}\right.$ and $\left.\dot{\mathrm{Q}}_{\mathrm{Int}, \mathrm{B}-\mathrm{C}}\right)$.

Three more equations can be written as combinations of the Equations (3) to (6):

Assuming a control volume around the whole turbocharger, equation (7):

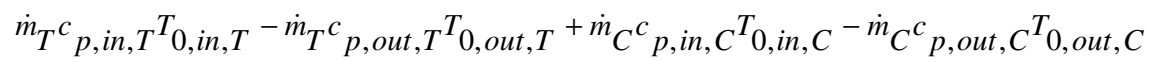

$-\dot{Q}_{W}-\dot{Q}_{O i l}-\dot{Q}_{E x t, T}-\dot{Q}_{E x t, C}-\dot{Q}_{E x t, B}=0$

Assuming a control volume around the turbine and bearing housings, Equation (8):

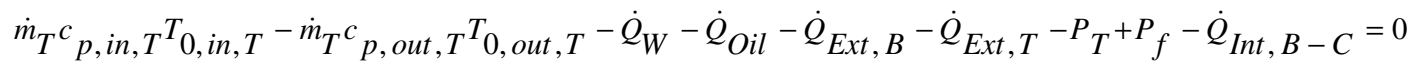

Assuming a control volume around the compressor and bearing housings, Equation (9):

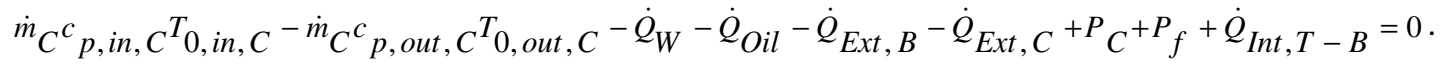


These equations were used to tune the heat transfer coefficients on the turbocharger. Insulators such as gaskets between pipes and the turbocharger, which has a thermal contact resistance, make the amount of heat conducted to the piping negligible. Additionally, the surface temperature of the turbine back is much lower than the turbine housing surface temperature due to the thermal contact resistance.

Three main heat transfer mechanisms are:

$\dot{Q}_{\text {Cond }}=k A \frac{\Delta T}{\Delta x}$

$\dot{Q}_{\text {Rad }}=\varepsilon \sigma A\left(T^{4}-T_{\infty}^{4}\right)$

$\dot{Q}_{C o n v}=h A\left(T-T_{\infty}\right)$

The convection heat transfer coefficient can be calculated by Equation (13):

$h_{D}=\frac{N u_{D} k}{D}$.

The Nu number for forced and natural convection heat transfers can be calculated by the following equations, respectively [19]:

$$
\begin{gathered}
N u=a \operatorname{Re}^{b} \operatorname{Pr}^{c} \\
N u_{D}=d G r_{D}^{e} \operatorname{Pr}^{f} .
\end{gathered}
$$

The empirical constants $a, b, c, d, e$, and f depend on the surface geometry and flow conditions. For a circular cylinder, $\mathrm{c}$ is assumed to be 0.33 [19]. The Reynolds, Prandtl, and Grashof numbers are calculated by the following equations, respectively:

$$
\begin{aligned}
& \operatorname{Re}_{D}=\frac{U_{\infty} D}{v} \\
& \operatorname{Pr}=\frac{c_{p} \mu}{k} \\
& G r_{D}=\frac{g \beta\left(T_{w}-T_{\infty}\right) D^{3}}{v^{2}} .
\end{aligned}
$$

It must be noted that fluid properties are evaluated at the film temperature, which is the average of the surface and free-stream temperatures. For an ideal gas, the volumetric thermal expansion coefficient is $\beta=1 / T$ where $T$ is the absolute temperature of the gas.

Before solving a heat transfer problem, it is very important to realize that the convection heat transfer can be purely natural convection, purely forced convection, or a combination of natural and forced convection. The type of convection heat transfer can be defined by the ratio of the Gr to the square of the $\operatorname{Re}[19]$ :

Natural convection neglected

$\operatorname{Gr} / \mathrm{Re}^{2} \ll 1$ 
Forced/natural convection comparable

$$
G r / \operatorname{Re}^{2}=1
$$

Forced convection neglected

$$
G r / \operatorname{Re}^{2}>1
$$

If the forced and natural convection are comparable, both must be considered by the following equation [19]:

$\overline{N u^{n}}=\left|\overline{N u_{F}^{n}} \pm \overline{N u_{N}^{n}}\right|$

The constant ( $\mathrm{n})$ and the sign in this equation depend on the body shape and the direction of the flow around the shape, respectively [19].

\section{Results and discussions}

\subsection{Comparison of different methods}

To assess different methods of calculating heat transfer on the turbocharger, seven methods were compared to each other and finally a new method is suggested. The external heat transfer of the turbocharger is the summation of the external heat transfers of the turbine housing and back, the compressor housing and back, and the bearing housing:

$$
\dot{Q}_{E x t, T u r b o}=\dot{Q}_{E x t, T}+\dot{Q}_{E x t, C}+\dot{Q}_{E x t, B}
$$

This can be calculated by combining Equations (7) and (20) in equation (21), which is turbocharger energy balance, obtained from the measurements:

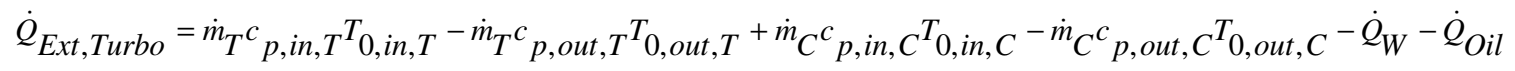

The external heat transfer of each part of the turbocharger consists of radiation and convection. Equation (20) can be also calculated based on the mentioned equations for radiation and convection. The convection heat transfer, however, is the problematic part of heat transfer calculation. Nu numbers were calculated for the compressor housing and back, the turbine housing and back, and the bearing housing. The seven methods for calculating the Nu number of turbocharger components are summarized in Table 5 in terms of the constants of Equations (14) and (15). Method 4 is the combined forced and natural convection (methods 2 and 3) based on Equation (19), considering $\mathrm{Gr} / \mathrm{Re}^{\wedge} 2$.

Figure 3 shows the calculated external heat transfer of the turbocharger versus Equation (21) for trials in Table 4 based on the methods summarized in Table 5 for Nu calculation. In this figure the results should lie on the black line as this indicates that the external heat transfers of the turbocharger derived from the heat transfer model and the actual measurements of heat transfer are equal. Although all methods predict the heat transfer of the turbocharger well in low external heat transfer of the turbocharger, they underestimate significantly the external heat transfer on the right side of the figure. Trials 3 to 6 are the load points when the fan is blowing on the turbocharger and the $R e$ numbers are high on turbocharger components. 
Table 5. The empirical constants a, b, c, d, e, and $f$ in Equations (14) and (15) for Nu number calculation of turbocharger components from literature. The numbers in brackets refer to the reference for each method.

\begin{tabular}{|c|c|c|c|c|c|c|c|}
\hline Method & 1 [2] & 2 [3] & 3 [3] & $4[19]$ & 5 [19] & $6[19]$ & $7[19]$ \\
\hline $\begin{array}{l}\text { Turbine } \\
\text { housing }\end{array}$ & $\begin{array}{l}d=0.667 \\
e=0.25 \\
f=0.25\end{array}$ & $\begin{array}{l}d=0.2 \\
e=0.25 \\
f=0.25\end{array}$ & $\begin{array}{l}a=0.6 \\
b=0.4 \\
c=0.33\end{array}$ & $\begin{array}{l}\text { Combined methods } 2 \text { and } \\
3 \text {, considering } \mathrm{Gr} / \mathrm{Re}^{\wedge} 2\end{array}$ & $\begin{array}{l}a=0.683 \\
b=0.466 \\
c=0.33\end{array}$ & $\begin{array}{l}a=0.193 \\
b=0.618 \\
c=0.33\end{array}$ & $\begin{array}{l}a=0.0266 \\
b=0.805 \\
c=0.33\end{array}$ \\
\hline $\begin{array}{l}\text { Compressor } \\
\text { housing }\end{array}$ & $\begin{array}{l}d=0.667 \\
e=0.25 \\
f=0.25\end{array}$ & $\begin{array}{l}d=0.678 \\
e=0.25 \\
f=0.25\end{array}$ & $\begin{array}{l}a=0.032 \\
b=0.8 \\
c=0.43\end{array}$ & $\begin{array}{l}\text { Combined methods } 2 \text { and } \\
3 \text {, considering } \mathrm{Gr} / \mathrm{Re}^{\wedge} 2\end{array}$ & $\begin{array}{l}a=0.683 \\
b=0.466 \\
c=0.33\end{array}$ & $\begin{array}{l}a=0.193 \\
b=0.618 \\
c=0.33\end{array}$ & $\begin{array}{l}a=0.0266 \\
b=0.805 \\
c=0.33\end{array}$ \\
\hline $\begin{array}{l}\text { Bearing } \\
\text { housing }\end{array}$ & $\begin{array}{l}d=0.53 \\
e=0.25 \\
f=0.25\end{array}$ & $\begin{array}{l}d=0.678 \\
e=0.25 \\
f=0.25\end{array}$ & $\begin{array}{l}a=0.6 \\
b=0.4 \\
c=0.33\end{array}$ & $\begin{array}{l}\text { Combined methods } 2 \text { and } \\
3 \text {, considering } \mathrm{Gr} / \mathrm{Re}^{\wedge} 2\end{array}$ & $\begin{array}{l}a=0.683 \\
b=0.466 \\
c=0.33\end{array}$ & $\begin{array}{l}a=0.193 \\
b=0.618 \\
c=0.33\end{array}$ & $\begin{array}{l}a=0.0266 \\
b=0.805 \\
c=0.33\end{array}$ \\
\hline Turbine back & $\begin{array}{l}d=0.53 \\
e=0.25 \\
f=0.25\end{array}$ & $\begin{array}{l}d=0.2 \\
e=0.25 \\
f=0.25\end{array}$ & $\begin{array}{l}a=0.6 \\
b=0.4 \\
c=0.33\end{array}$ & $\begin{array}{l}\text { Combined methods } 2 \text { and } \\
3 \text {, considering } \mathrm{Gr} / \mathrm{Re}^{\wedge} 2\end{array}$ & $\begin{array}{l}a=0.68 \\
b=0.5 \\
c=0.33\end{array}$ & $\begin{array}{l}a=0.664 \\
b=0.5 \\
c=0.33\end{array}$ & $\begin{array}{l}a=0.037 \\
b=0.8 \\
c=0.33\end{array}$ \\
\hline $\begin{array}{l}\text { Compressor } \\
\text { back }\end{array}$ & $\begin{array}{l}d=0.667 \\
e=0.25 \\
f=0.25\end{array}$ & $\begin{array}{l}d=0.678 \\
e=0.25 \\
f=0.25\end{array}$ & $\begin{array}{l}a=0.032 \\
b=0.8 \\
c=0.43\end{array}$ & $\begin{array}{l}\text { Combined methods } 2 \text { and } \\
3 \text {, considering } \mathrm{Gr} / \mathrm{Re}^{\wedge} 2\end{array}$ & $\begin{array}{l}a=0.68 \\
b=0.5 \\
c=0.33\end{array}$ & $\begin{array}{l}a=0.664 \\
b=0.5 \\
c=0.33\end{array}$ & $\begin{array}{l}a=0.037 \\
b=0.8 \\
c=0.33\end{array}$ \\
\hline
\end{tabular}

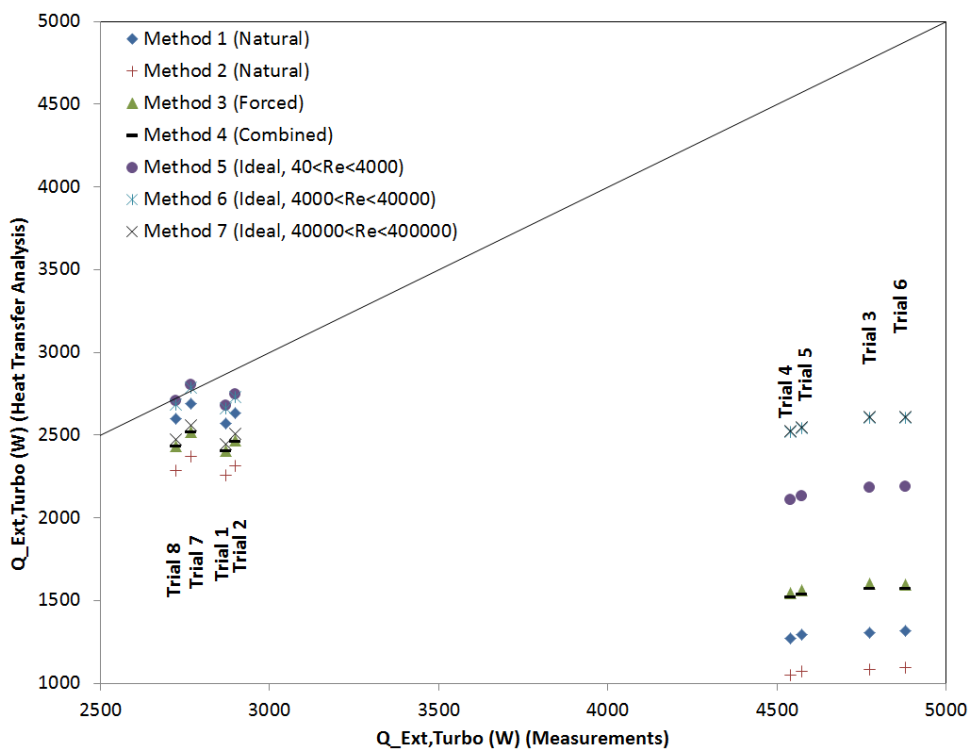

Figure 3. The calculated external heat transfer (vertical axis) against the measured external heat transfer of the turbocharger (horizontal axis) for trials summarized in Table 4 and by the mentioned methods in Table 5 .

To check the reason for this underestimation, Figure 4 illustrates the Nu number calculation based on Re number and different constants in Equation (14). According to the measurements, the Pr number for all turbocharger components were between 0.69 and 0.7 for several load points and heat transfer conditions. Therefore, $\mathrm{Pr}$ is considered 0.69 just in this figure, and constant $c$ is 0.33 for all cases; However, constant $b$ is changed from 0.4 to 0.9 and constant $a$ is tuned to get almost a same Nu number in low Re numbers. Apparently, all methods can give the Nu number in a same order at low Re numbers; However, they begin to deviate from each other significantly after Re number of 3000 . This is the reason for underestimation of external heat transfer of the turbocharger in Figure 3 at high Re numbers. None of the methods in Table 5 has a high constant $b$ (power of Re number), therefore, the predicted Nu is low and the convection heat transfer is underestimated. 


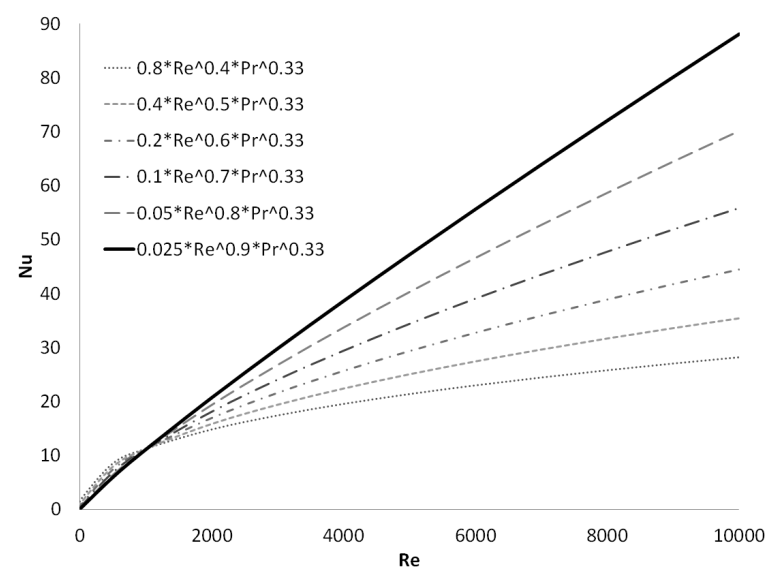

Figure 4. Nu vs. Re with different constants in Equation (14), $\operatorname{Pr}=0.69 ; c=0.33 ; b$ is varied and a is tuned to get a same result in low $\operatorname{Re}$ numbers.

The measurements in this study enable us to tune the constants of Equation (14) in order for heat transfer calculation. Therefore, Figure 5 examines all the engine load points under different heat transfer conditions listed in Table 3 to produce the same figure as Figure 3 while the last method is a suggestion based on the present study. The suggested method assumes that the heat transfer is by forced convection, Equation (14), and that the constant c in this equation should be $\mathbf{0 . 3 3}$, which is the case for a circular cylinder under forced convection conditions and is what was used in reference [3]. Constants $a$ and $b$ are selected in an iterative process to achieve a linear correlation between the modelled and measured heat transfers. The results shown in Figure 5 propose that the suggested method provides the best correlation between calculated heat transfer values and those obtained from experimental measurements. The Nu number can be calculated by Equation (22) based on the present study:

$$
\overline{N u}=0.025 \operatorname{Re}^{0.9} \operatorname{Pr}^{0.33} \quad \operatorname{Pr}>0.6
$$

which is valid for the turbine housing, turbine back, bearing housing, compressor back, and compressor housing over a wide range of $\mathrm{Re}$ and engine operating conditions.

Figure 6 shows the Nu number of the turbine housing against $\mathrm{Gr} / \mathrm{Re}^{\wedge} 2$ for the cases listed in Table 3by the suggested method comparing with some other methods and a focus on very low $\mathrm{Gr} / \mathrm{Re} \mathrm{e}^{\wedge} 2$. As mentioned before, in very low $\mathrm{Gr} / \mathrm{Re}^{\wedge} 2$, the convection heat transfer is purely forced convection. As it is clear, methods 1 and 2 which are for natural convection provide almost constants Nu numbers over a wide range of $\mathrm{Gr} / \mathrm{Re}^{\wedge} 2$ and Nu numbers are linear functions of $\mathrm{Gr} / \mathrm{Re}^{\wedge} 2$. Method 3 which is for forced convection provides almost the same Nu number as method 2 (natural convection) at high $\mathrm{Gr} / \mathrm{Re}^{\wedge} 2$ while it begins to rise in very low $\mathrm{Gr} / \mathrm{Re}^{\wedge} 2$ by a power function. When $\mathrm{Gr} / \mathrm{Re}^{\wedge} 2$ is very low, Re is very high; if the power of Re in Equation (14), constant b, is low then the effect of Re would be low. Therefore, $b$ should be increased. Method 7 which has higher b provides higher $\mathrm{Nu}$ in very low $\mathrm{Gr} / \mathrm{Re}^{\wedge} 2$; However, it does not still agree with the experiment. The suggested power function could give much higher Nu at very low 
$\mathrm{Gr} / \mathrm{Re}^{\wedge} 2$ and a same Nu at high $\mathrm{Gr} / \mathrm{Re}^{\wedge} 2$. This analysis checked for other turbocharger components and the same trends were observed.

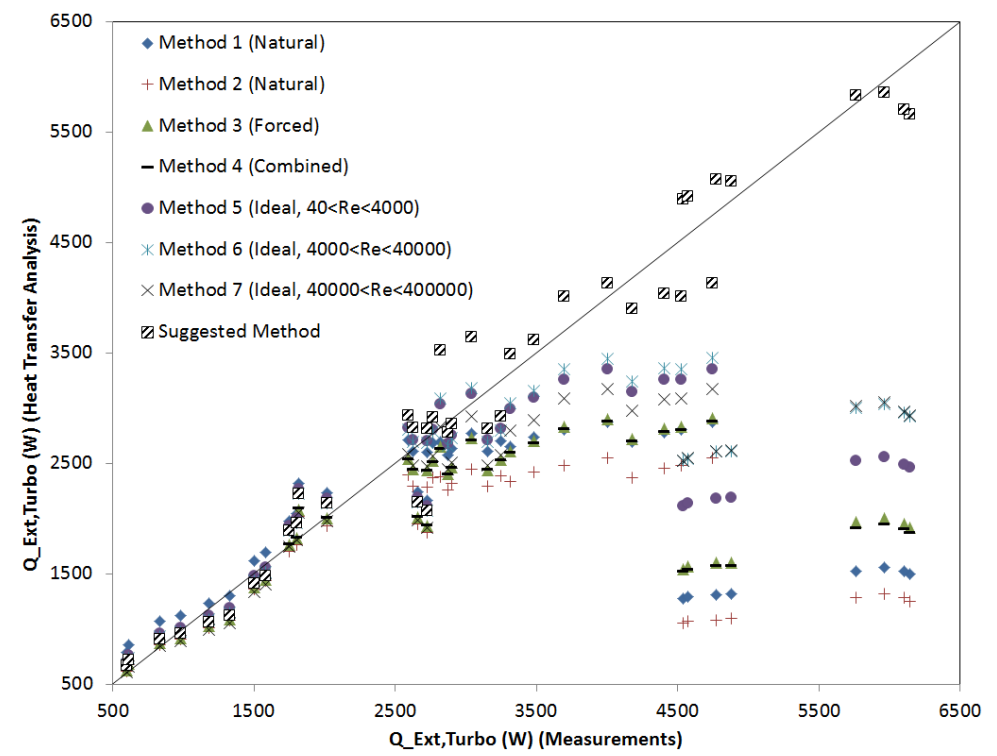

Figure 5. The calculated external heat transfer (vertical axis) against the measured external heat transfer of the turbocharger (horizontal axis) for the cases summarized in Table 3.

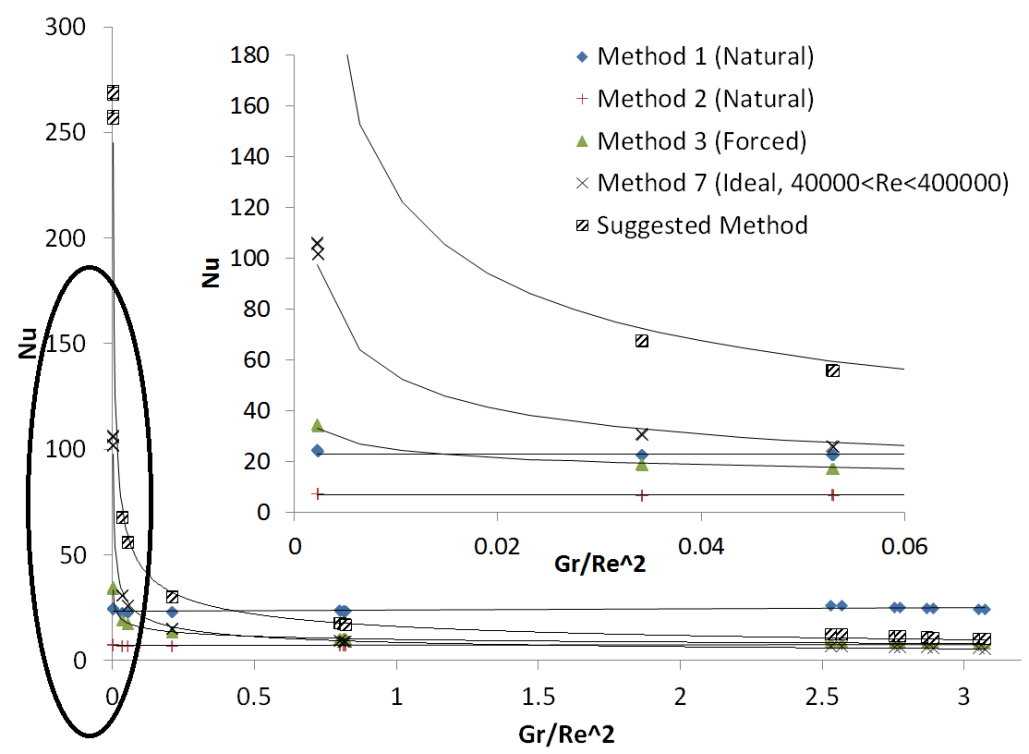

Figure 6. Nu of the turbine housing vs. $\mathrm{Gr} / \mathrm{Re}^{\wedge} 2$ for the cases listed in Table 3, and a focus on very low $\mathrm{Gr} / \mathrm{Re}^{\wedge} 2$.

The results indicate that the heat transfer calculation is highly dependent on the constants and coefficients that are used in the calculation (listed in Table 5), and the material properties and shapes of the turbocharger components might also result in uncertainties in the heat transfer calculations. The limitation on being able to rapidly measure the temperatures is also a source of error in the calculations based on the heat transfer model. According to Baines et al. [3], the greatest uncertainty lies in the convection heat transfer constants and any errors or uncertainties in the other selected parameters will be subsumed into the convection heat transfer coefficients and correlations. 
It should be noted that despite the fact that different turbocharger test facilities might lead to different heat transfer evaluation, a reliable method should be picked up for this specific turbocharger and engine to be able to continue this study in evaluating the different heat transfer conditions on the turbocharger. Therefore, we used the suggested method in the remainder of this work.

\subsection{Magnitudes of the energy fluxes on the turbocharger}

To make approximate comparisons between the energy fluxes on the turbocharger, orders of magnitude of the energy fluxes are used. Order of magnitude is an estimate of magnitude stated as a power of ten. For instance, if two numbers differ by " $\mathrm{n}$ " order of magnitude, they differ by a factor of about $10^{n}$. Figure 7 shows the amount of energy fluxes on the turbocharger and their orders of magnitude for trial 8 in Table 4 based on the heat transfer model of the turbocharger. The largest energy flux is the enthalpy difference across the turbine, and the smallest heat transfer mechanism on the turbocharger is the bearing housing heat transfer to the ambient. This is because the cooling water passes through the bearing housing and the wall temperature is close to the water temperature (from 17 to $23^{\circ} \mathrm{C}$ ) such that the rate of convection and radiation heat transfer is very low. The results show that the enthalpy difference across the turbine and the compressor, the turbine power, and the compressor power have the same order of magnitude of three. Interestingly, the external heat transfer of the turbine housing, the internal heat transfer from the turbine to the bearing housing, and the heat transfer via the water have the same order of magnitude as the turbine power. However, the orders of magnitude of the internal heat transfer from the bearing housing to the compressor and the oil heat transfer are one order lower than the turbine power. The results also show that the external heat transfer of the compressor housing, the external heat transfer of the bearing housing, and the frictional power all have an order of magnitude of one that is the lowest order of magnitude so these parameters do not play an important role in the heat transfer analysis of the turbocharger.

The internal heat transfer from the turbine to the bearing housing $\left(\mathrm{Q}_{\text {Int,T-B}}\right)$ and from the bearing housing to the compressor $\left(\mathrm{Q}_{\mathrm{Int,B-C}}\right)$ are significant in this heat transfer analysis of the turbocharger. They include all heat transfers from the turbine to the bearing housing and from the bearing housing to the compressor such as conduction heat transfer via the turbo-shaft, conduction heat transfer via the bearing housing material, heat transfer via the cooling oil, and heat transfer via the cooling water. The order of magnitude of the heat transfer of the turbocharger depends on the water inlet temperature, water mass flow, cooling air temperature, and cooling air mass flow so a general conclusion should not be made in regards to the magnitude of energy fluxes of turbochargers from these results.

\subsection{Evaluation of different heat transfer conditions}

When evaluating the different heat transfer conditions on the turbocharger, five heat fluxes have been considered, even some of them are two orders of magnitude lower than the rest, as discussed previously. Therefore, the analysis includes the external heat transfers on the turbine, the compressor, and the bearing housing and the internal heat 
transfers from the turbine to the bearing housing and from the bearing housing to the compressor. Figure 8 shows the magnitude of these heat fluxes for the trials listed in Table 4. The results indicate that the effect of the fan on the energy balance of the turbocharger is significant (trials 3 to 6 in Figure 8). The different heat transfer conditions did not change the orders of magnitude of the internal heat transfers from the turbine to the bearing housing or from the bearing housing to the compressor, nor of the external heat transfer on the turbine housing. However, the fan (trails 3 to 6) increases the order of magnitude of the external heat transfer of the compressor housing. In addition, the presence of cooling water (for instance compare trial 8 with trial 7) could change the external heat transfer on the bearing housing by one order of magnitude.

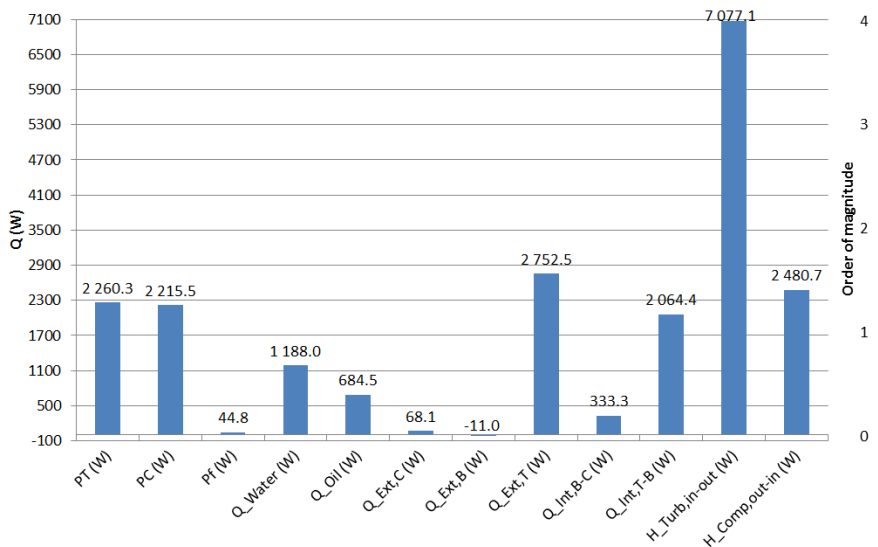

(a)

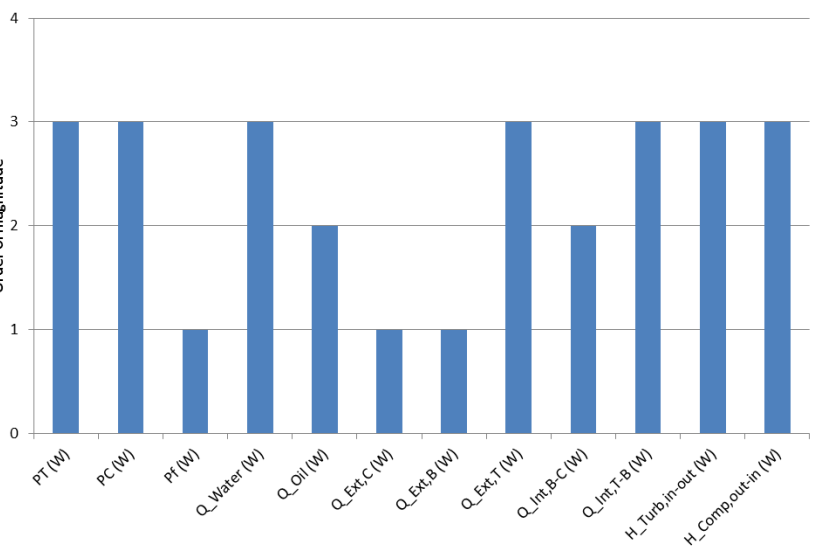

(b)

Figure 7. a) Energy fluxes on the turbocharger for trial 8 in Table 4. b) Orders of magnitude of the heat transfer mechanisms and energy fluxes on the turbocharger for trial 8 in Table 4.

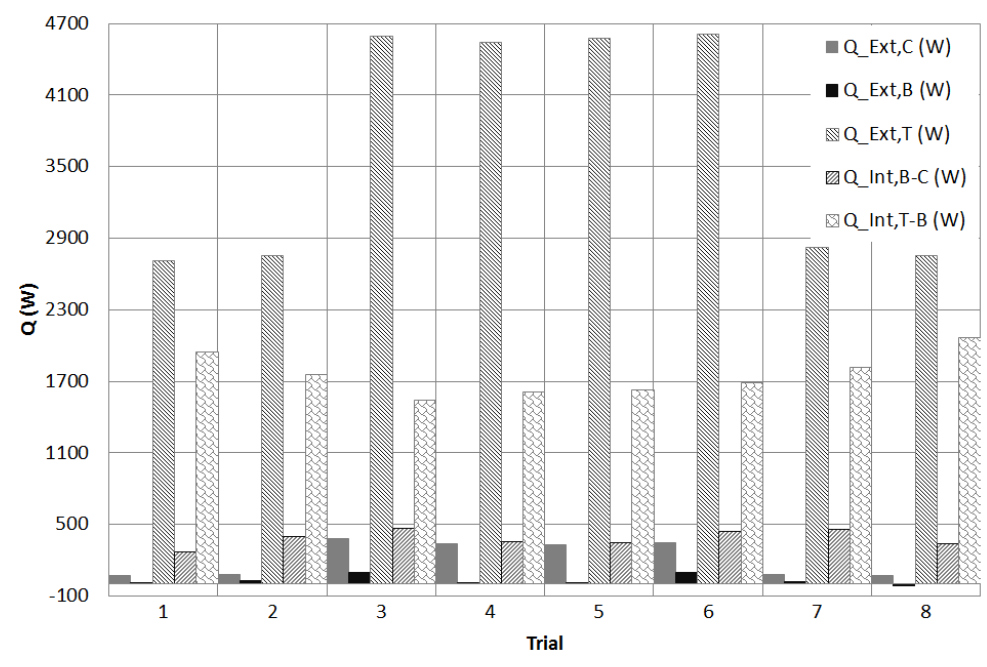

Figure 8. Heat fluxes on the turbocharger for the trials listed in Table 4.

Figure 9 shows the results of the analysis of the turbocharger heat transfer model based on Equations (1) and (2). The effects of the three variables (water, fan, and radiation shield) and their interactions are shown for each heat flux measurement. A negative effect of a variable on a response means that the existence of the variable decreases the 
response. The effects of the fan on all heat fluxes are significant. However, the effect of the water is more significant on the internal heat transfer from the bearing housing to the compressor, the internal heat transfer from the turbine to the bearing housing, and the external heat transfer of the bearing housing. It appears that the radiation shield between the turbine and the compressor has no significant effect on the energy balance of the turbocharger, but it does prevent a small amount of radiation heat transfer from the turbine back to the bearing housing. The small effect of the turbocharger radiation shield might also be due to the small surface areas of the turbine back and the compressor back and the low surface temperatures on these surfaces.

The presence of the radiation shield in Figures $9 \mathrm{a}$ and $9 \mathrm{~b}$ shows some positive effect. This is because the radiation shield prevents the radiation heat transfer from the turbine to the compressor housing back and the bearing housing. The assumed directions of the external heat transfers of the compressor and the bearing housings are from the wall to the environment as can be seen in Figure 2. Therefore, the radiation shield makes the external heat transfers from the compressor housing and the bearing housing more positive, and the radiation shield has a slightly negative effect on the external heat transfer from the turbine housing, as shown in Figure 9e.

Figure $9 \mathrm{c}$ shows that water is the most important factor that affects the internal heat transfer from the bearing housing to the compressor. Conduction through the bearing housing to the compressor depends on the temperature gradient between the bearing housing and the compressor, and the bearing housing temperature is greatly influenced by the water heat flow.

Figure $9 \mathrm{c}$ also shows that the fan encourages the heat transfer from the bearing housing to the compressor. The "Fan" increases the external heat transfer of the bearing housing (see Figure 9b), and its temperature decreases. On the other hand, the effect of the fan on the external heat transfer of the compressor housing is higher compared to the bearing housing, as shown in Figures $9 \mathrm{a}$ and $9 \mathrm{~b}$. The compressor housing temperature is a function of the compressed air temperature and the external heat transfer conditions. Additionally, the heat transfer condition cannot greatly influence the compressor pressure ratio [20,21]. As a result, the compressor housing temperature is decreased by the fan but the bearing housing temperature is not significantly affected in the core due to the hot oil flow around the shaft. Therefore, the temperature gradient between the bearing housing and compressor increases and the fan increases the internal heat transfer from the bearing housing to the compressor.

The question that arises is why the effect of using the fan on the internal heat transfer from the bearing housing to the compressor is positive, but this effect is negative for the internal heat transfer from the turbine to the bearing housing (Figure 9d). This is because of the large effect the fan has on the external heat transfer of the turbine housing, as can be seen in Figure 9e, compared to the low effect of the fan on the external heat transfer of the bearing housing, as shown in Figure 9b. Hence, the temperature decrease on the turbine housing is much higher than the 
bearing housing and this leads to a lower temperature gradient between the turbine and the bearing housing. As a result, the effect of the fan on the internal heat transfer from the turbine to the bearing housing is negative.

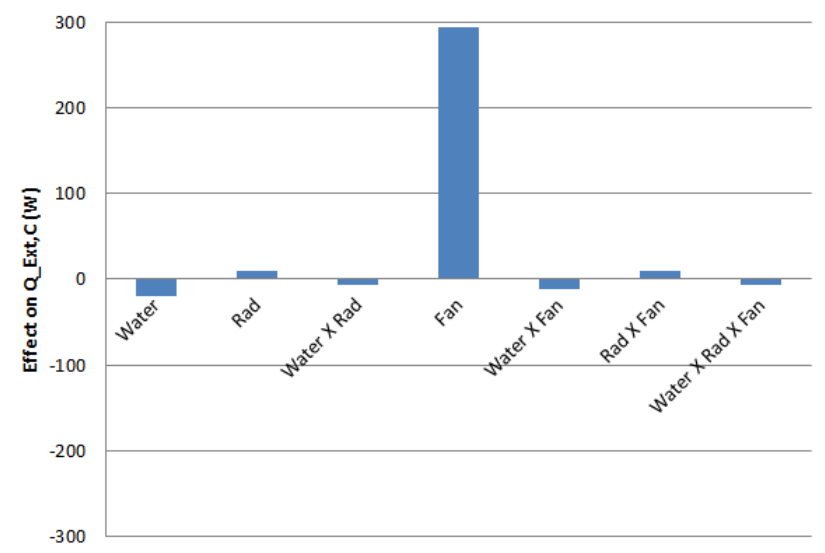

(a)

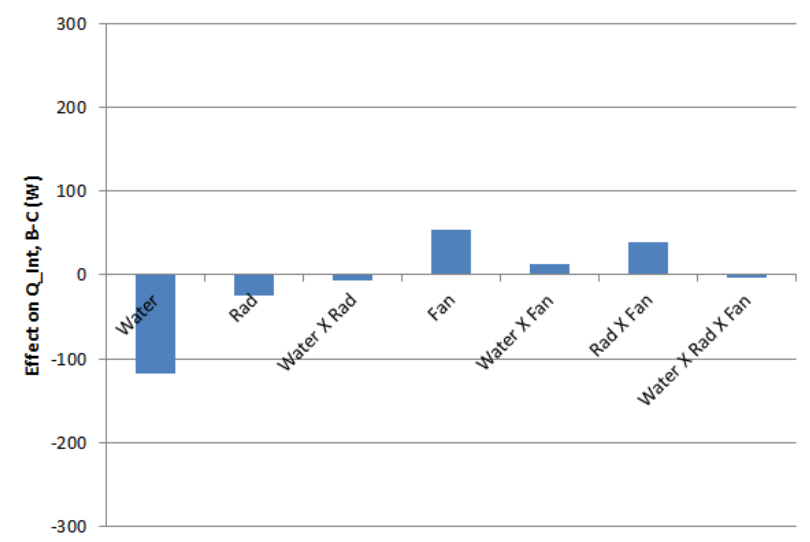

(c)

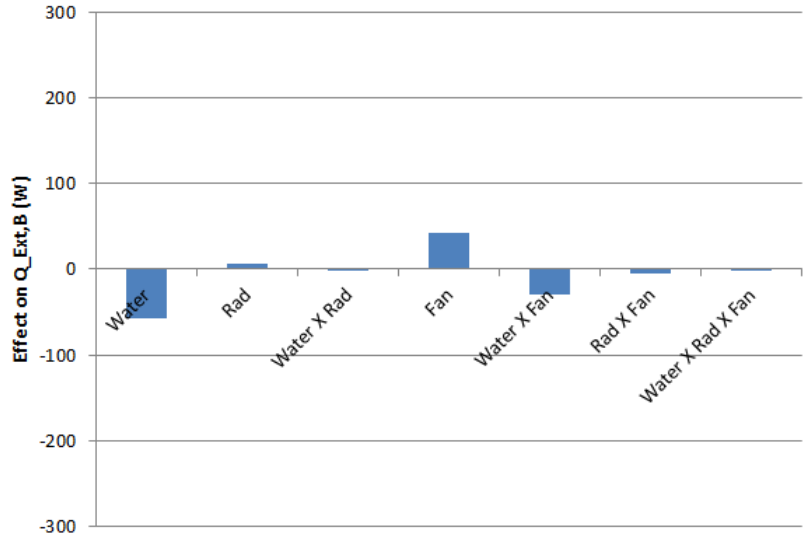

(b)

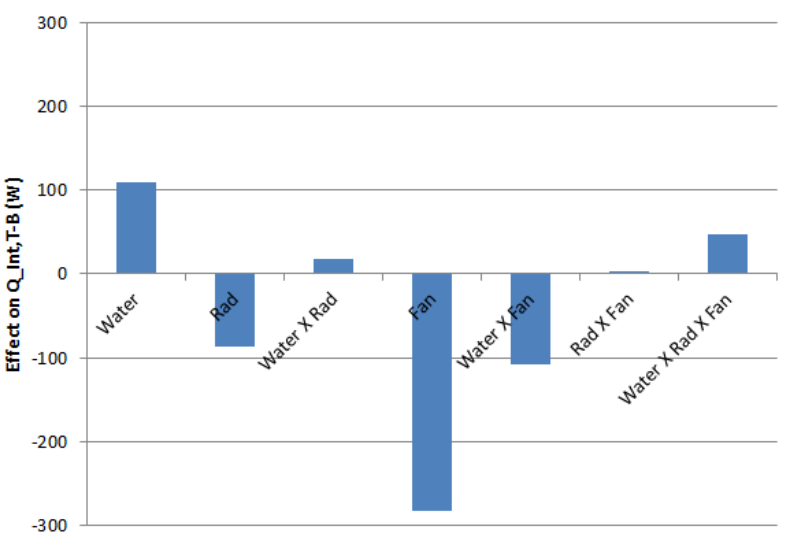

(d)

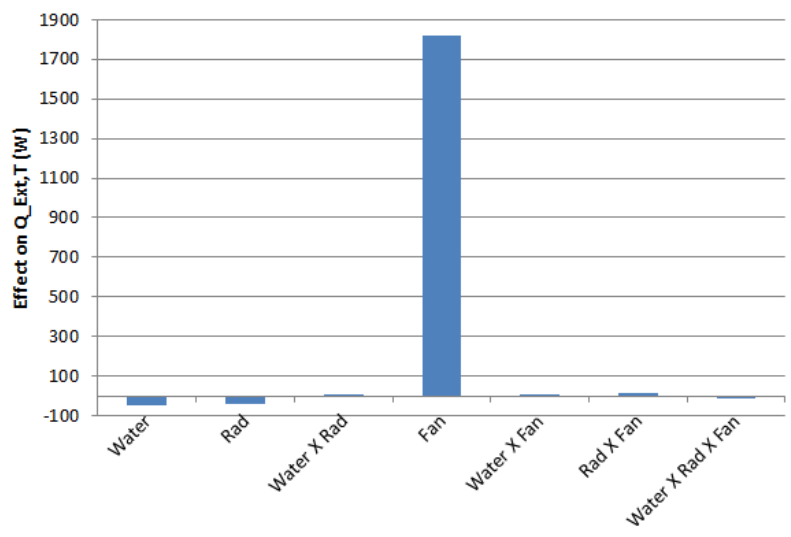

(e)

Figure 9. Effects of different heat transfer conditions for the trials listed in Table 4 on a) the external heat transfer of the compressor; b) the external heat transfer of the bearing housing; c) the internal heat transfer from the bearing housing to the compressor; d) the internal heat transfer from the turbine to the bearing housing; and e) the external heat transfer of the turbine.

Figure $9 \mathrm{~d}$ shows that passing water through the bearing housing increases the internal heat transfer from the turbine housing to the compressor. This can be explained by examining Figure 9c that shows that passing the water through the bearing housing decreases the external heat transfer from the bearing housing. This means that the 
bearing housing wall temperature gets closer to the water temperature, which is close to the ambient temperature in this experiment. Thus, the temperature difference increases between the turbine and the bearing housing. As a result, the internal heat transfer from the turbine to the bearing housing increases when the water passes through the bearing housing.

The fan, the water, the interaction of the fan and the water ("Water $\times$ Fan"), and the turbocharger radiation shield ("Rad") are the most significant factors that affect the internal heat transfer from the turbine to the bearing housing as shown in Figure 9d. The fan decreases the internal heat transfer from the turbine to the bearing housing, whereas the water increases this heat transfer. As a result, the interaction of the water and the fan ("Water $\times$ Fan") counteracts their effects on the internal heat transfer from the turbine to the bearing housing. Other significant effects on turbocharger heat fluxes are the interaction of the radiation shield and the fan ("Rad $\times$ Fan") on the internal heat transfer from the bearing housing to the compressor (see Figure 9c) and the interaction of the water and the fan ("Water $\times$ Fan") on the external heat transfer of the bearing housing (see Figure 9b).

\section{Conclusions}

To analyse heat transfer of an on-engine turbocharger in different heat transfer conditions, a heat transfer model was developed and validated against measurements in an innovative DOE with aid of turbocharged engine simulation in which the heat transfer of the turbocharger was included. This was performed at several engine speeds and loads and under different heat transfer conditions on the turbocharger including a number of convection and radiation heat transfer conditions on the turbocharger and conduction heat transfer conditions through the turbocharger. Several thermocouples were welded on accessible surfaces of the turbocharger to calculate the external heat transfers.

After examining several methods for calculating the external heat transfer of the turbocharger components, a new formula was suggested based on the current study for calculating the Nu number as a function of Re and Pr numbers. This equation is valid for the turbine housing, the turbine back, the bearing housing, the compressor back, and the compressor housing over wide ranges of Re and engine operating conditions.

The results of this study indicate that the internal heat transfers from the turbine to the bearing housing and from the bearing housing to the compressor are significant. Interestingly, the external heat transfer of the turbine housing, the internal heat transfer from the turbine to the bearing housing, and the heat transfer via the coolant water have the same order of magnitude as the turbine power even though the order of magnitude of the heat transfer depends on water inlet temperature and water mass flow.

The different heat transfer conditions did not change the orders of magnitude of the internal heat transfers from the turbine to the bearing housing or from the bearing housing to the compressor, nor did they change the order of 
magnitude of the external heat transfer on the turbine housing. However, the effect of using an extra cooling fan is significant on the energy balance of the turbocharger and is a key factor for changing convection heat transfer, which depends on mass flow and the temperature of the cooling air. In addition, the effect of the coolant water is more significant on the external heat transfer of the bearing housing and the internal heat transfer from the bearing housing to the compressor. It appears that the radiation shield between the turbine and the compressor has no significant effect on the energy balance of the turbocharger.

Conduction through the bearing housing to the compressor depends on the temperature gradient between the bearing housing and the compressor, and the bearing housing temperature is greatly influenced by the water heat flow. The internal heat transfer from the turbine to the bearing housing increases when the water passes through the bearing housing; however, this reduces when the velocity of the air around the turbocharger is increased by the fan.

\section{Funding}

The Swedish Energy Agency and Royal Institute of Technology (KTH) sponsored this work within the Competence Centre for Gas Exchange (CCGEx).

\section{References}

[1] Romagnoli A and Martinez-Botas R, "Heat Transfer Analysis in a Turbocharger Turbine: An Experimental and Computational Evaluation," Applied Thermal Engineering, vol. 38, pp. 58-77, 2012.

[2] Romagnoli A and Martinez-Botas R, "Heat Transfer on a Turbocharger under Constant Load Points," ASME Turbo Expo 2009, Power for Land, See and Air, GT 2009-59618, 2009.

[3] Baines N, Wygant KD, and Dris A, "The Analysis of Heat Transfer in Automotive Turbochargers," Journal of Engineering for Gas Turbine and Power, April 2010, Vol. 132/042301-1., vol. 132, 042301-1, April 2010.

[4] Serrano JR, Olmeda P, Paez A, and Vidal F, "An Experimental Procedure to Determine Heat Transfer Properties of Turbochargers," Measurement Science Technology, vol. 21, 035109 (14pp), 2010.

[5] Bohn D, Heuer T, and Kusterer K, "Conjugate Flow and Heat transfer Investigation of a Turbocharger," Journal of Engineering for Gas Turbine and Power, July 2005, Vol. 127/663, vol. 127, no. 663, July 2005.

[6] Galindo J, Lujan JM, Serrano JR, Dolz V, and Guilain S, "Description of a Heat Transfer Model Suitable to Calculate Transient Processes of Turbocharged Diesel Engines with One-Dimensional Gas-Dynamic Codes," Applied Thermal Engineering, vol. 26, 2006.

[7] Cormerais M, Chesse P, and Hetet JF, "Turbocharger Heat Transfer Modeling Under Steady and Transient Conditions," Int. J. of Thermodynamics, vol. 12, no. 4, pp. pp. 193-202, Dec 2009.

[8] Serrano JR, Guardiola C, Dolz V, and Tiseira A, "Experimental Study of the Turbine Inlet Gas Temperature Influence on the Turbocharger Performance," SAE, 2007-01-1559, 2007.

[9] Sirakov B and Casey M, "Evaluation of Heat Transfer Effects on Turbocharger Performance," Journal of Turbomachinery, vol. 135, GT 2011-45887, 2013.

[10] Aghaali $\mathrm{H}$ and Angstrom H, "Improving Turbocharged Engine Simulation by Including Heat Transfer in the Turbocharger," SAE Technical Paper, 2012-01-0703, 2012.

[11] Serrano J, Olmeda P, Arnau F, Reyes-Belmonte M, and Lefebvre A, "Importance of Heat Transfer Phenomena in Small Turbochargers for Passenger Car Applications," SAE Int. J. Engines, vol. 6, no. 2, pp. 716-728, 2013-010576, 2013.

[12] Aghaali $\mathrm{H}$ and Angstrom HE, "Temperature Estimation of Turbocharger Working Fluids and Walls under Different Engine Loads and Heat Transfer Conditions," SAE Technical Paper, 2013-24-0123, 2013.

[13] Larsson PI, Westin F, Andersen J, Vetter J, and Zumeta A, Eds., "Efficient Turbo Charger Testing," MTZ 
worldwide, vol. 70, pp. p.16-21, 07-08 2009.

[14] Aghaali H, "On-Engine Turbocharger Performance Considering Heat Transfer," Machine Design, Stockholm, Licentiate thesis, KTH Royal Institute of Technology, Trita-MMK 2012:08; ISSN 1400-1179, 2012. [Online]. http://kth.divaportal.org/smash/record.jsf;jsessionid=1015058e07e033ac2851b955e781 ?searchld=1\&pid=diva2:524801\&rvn=2

[15] MoreSteam.com The Engine Room of Continuous Improvement. [Online]. http://www.moresteam.com/toolbox/design-of-experiments.cfm

[16] (2012) Wikipedia The Free Encyclopedia. [Online]. http://en.wikipedia.org/wiki/Factorial experiment

[17] Box GEP, Hunter WG, and Hunter JS, Statistics for Experimenters, Wiley series, 1978.

[18] Technologies G, "GT-POWER User's Manual and Tutorials," , GT-SUITE Version 7.1, 2010.

[19] Hagen KD, Heat Transfer with Applications, Upper Saddle River, N.J. Prentice Hall, cop, 1999.

[20] Aghaali $\mathrm{H}$ and Ångström HE, "Turbocharged SI-Engine Simulation with Cold and Hot-Measured Turbocharger Performance Maps," ASME Turbo Expo, GT2012-68758, 2012.

[21] Leufven $O$ and Eriksson L, "Investigation of compressor correction quantities for automotive applications," International Journal of Engine Research, vol. 13, no. 6, pp. 588-606, 2012.

\section{Appendix I}

\section{Notation}

\begin{tabular}{llllll}
\hline$A$ & Area $(\mathrm{m} 2)$ & $\mathrm{P}$ & Power $(\mathrm{W})$ & $v$ & Kinematic viscosity $\left(\mathrm{m}^{2} / \mathrm{s}\right)$ \\
$\mathrm{D}$ & Diameter $(\mathrm{m})$ & $\dot{Q}$ & Heat flux $(\mathrm{W})$ & $k$ & Thermal conductivity $(\mathrm{W} / \mathrm{m} \cdot \mathrm{K})$ \\
$\mathrm{T}$ & Temperature $(\mathrm{K})$ & $\mathrm{Nu}$ & Nusselt number & $\mathrm{h}$ & Convection heat transfer coefficient $\left(\mathrm{W} / \mathrm{m}^{2}\right)$ \\
$\mathrm{U}$ & Velocity $(\mathrm{m} / \mathrm{s})$ & $\mathrm{Pr}$ & Prandtl number & $\beta$ & Volumetric thermal expansion coefficient $(1 / \mathrm{K})$ \\
$\dot{m}$ & Mass flow $(\mathrm{kg} / \mathrm{s})$ & $G r$ & Grashof number & $c_{p}$ & Specific heat capacity at constant pressure $(\mathrm{J} / \mathrm{kg} \cdot \mathrm{K})$ \\
$\operatorname{Re}$ & Reynolds number & $\mathrm{g}$ & Standard gravity $\left(\mathrm{m} / \mathrm{s}^{2}\right)$ & $\sigma$ & Stefan-Boltzman constant $\left(\mathrm{W} / \mathrm{m}^{2} \cdot \mathrm{K}^{4}\right)$ \\
$\varepsilon$ & Emissivity & $\mu$ & Dynamic viscosity $(\mathrm{Pa} \cdot \mathrm{s})$ & & \\
\hline
\end{tabular}

\section{Subscripts}

\begin{tabular}{llllllllll}
\hline 0 & Total & in & Inlet & out & Outlet & D & Diameter & W & Water \\
C & Compressor & Int & Internal & Rad & Radiation & F & Forced & B-C & Bearing housing to compressor \\
T & Turbine & Ext & External & Conv & Convection & N & Natural & T-B & Turbine to bearing housing \\
B & Bearing housing & Turbo & Turbocharger & Cond & Conduction & f & Friction & $\infty$ & Free flow \\
\hline
\end{tabular}

